\title{
Human-wildlife conflict in the roof of the world: Understanding multidimensional perspectives through a systematic review.
}

\author{
Prashanti Sharma ${ }^{1}$, Nakul Chettri ${ }^{1}$, and Kesang Wangchuk ${ }^{1}$ \\ ${ }^{1}$ International Centre for Integrated Mountain Development
}

March 23, 2021

\begin{abstract}
Aim: Wildlife and their interaction human or human-wildlife conflict, though reported throughout human prehistory, its severity and complexity have increased in recent years. The Hindu Kush Himalaya region, rich and biodiversity and known as roof of the world have gained recognition for many conservation success but also with increasing trends of human-wildlife conflict. But, they are sparsely documented and the severity of its impacts are not known for the region. Hence, we present a systematic review on human-wildlife conflict from the roof of the world. Methods: We followed the systematic literature review (SLR) approach of qualitative content analysis, using Search, Appraisal, Synthesis, and Analysis (SALSA) framework and also used VOSViewer for spatial and network analysis.. Results: Our results based on 240 peer-reviewed articles till 2019 showed $57 \%$ increase of publications in the last decades but with disproportionate geographical and thematic focus. About $82 \%$ of the research reported cases are from protected area with large carnivores and mega-herbivores as major causes of the conflict. About $53 \%$ of the studies were questionnaire-based household and the results highlight habitat disturbance through land cover change, urbanization, and human population increase as major drivers of human-wildlife conflict. Traditional management techniques like guarding and fencing along with improvement in plans and policies have been reported. Our analysis of 681 keywords revealed prominent focus on 'human-wildlife conflict', 'Nepal', 'Bhutan', 'Snow Leopard' and 'Leopard' indicating the issue are linked with these species and countries. The involvement of 640 authors from 36 countries indicates increasing interest and Nepal and India are playing key role from the region. Main conclusions: There is spatial variation in research with limited regional and transboundary focus. Attention is needed on understanding the pattern of interactions including meso animals along with improved management interventions through integrated and transboundary cooperation for tackling the issue.
\end{abstract}

\section{Hosted file}

MS_Main_Revised.pdf available at https://authorea.com/users/403534/articles/514937-humanwildlife-conflict-in-the-roof-of-the-world-understanding-multidimensional-perspectivesthrough-a-systematic-review

\section{Hosted file}

MS_Figures.pdf available at https : //authorea.com/users/403534/articles/514937-human-wildlifeconflict-in-the-roof-of-the-world-understanding-multidimensional-perspectives-through-asystematic-review 